\title{
REEDUCAÇÃO E RECUPERAÇÃO DE FUNÇÕES MOTORAS: REGISTRO DE UM CASO COM INVERSÃO DE FUNÇÕES ENTRE MEMBROS SUPERIORES E INFERIORES
}

\author{
Abrão AnghinaH * \\ ANTONIO B. LEgÈVRE *:
}

Desde que Von Monakov introduziu o conceito de diásquise para explicar a recuperação funcional espontânea após lesões cerebrais, surgiram várias hipóteses que tentaram, não só ixplicar os mecanismos básicos deste processo como também correlacionar reeducação e retorno da função. De acordo com o conceito de diásquise (Forgays ${ }^{1}$ ), "os sintomas clínicos que surgem após lesões do córtex cerebral, poderão representar o déficit resultante, seja da destruição do tecido nervoso correspondente, seja da perturbação dos mecanismos de facilitação em áreas vizinhas que passam a funcionar inadequadamente. Durante a recuperação poderá ocorrer reorganização neural, isto é, as áreas corticais integras voltam a funcionar de forma efetiva, mesmo na ausência da facilitação original. Somente os sintomas clínicos residuais refletem, na realidade, a correlação direta com a área de tecido cerebral destruído." Esta teoria tem sofrido várias críticas, principalmente porque é extremamente difícil distinguir entre a recuperação espontânea e a devida à reabilitação.

Várias experiências em animais foram feitas, visando testar a teoria da diásquise; entretanto nenhuma apresentou resultados definitivos. $\mathrm{Na}$ opinião de Lashley ${ }^{2}$ o fato de Von Monakov não ter feito hipóteses para explicar o mecanismo da recuperação, "torna o processo um tanto misterioso". Pode-se admitir que a reeducação apressa o retorno da função, muito embora a recuperação espontânea possa ocorrer mais tardiamente. Forgays ${ }^{1}$, em análise critica, afirma que o único argumento realmente conclusivo do conceito de diásquise seria a demonstração de que o treinamento poderia determinar recuperação depois de se ter deixado, algum tempo, o indivíduo evoluir espontaneamente sem que fosse observada melhora nítida. Neste caso, é importante estabelecer que as funções readquiridas são as mesmas anteriormente perdidas e não meramente atividades de substituição (substituição funcional).

O propósito desta apresentação é registrar o caso inusitado de uma criança com retardo neuropsicomotor na qual ocorreu inversão de funções entre os membros superiores e inferiores. Procuraremos destacar alguns

Trabalho da Clínica Neurológica (Prof. Horácio M. Canelas) da Faculdade de Medicina da Universidade de São Paulo: * Assistente; "* Prof. Adjunto. 
aspectos das complexas relações existentes entre reeducação e recuperação da função motora. Deve ser destacado que a literatura a nosso alcance não registra caso semelhante.

\section{UBSER VACAO}

S.A.P, com 4 anos de idade, sexo feminino, branca, brasileira, internada em 19-02-1963 (Reg. 5.552) com diagnóstico de "encefalopatia a esclarecer". A paciente é filha única de pais sadios, nascida de parto normal, após 8 meses de gestação, pesando $1.600 \mathrm{~g}$; demorou muito para chorar, não ficou cianosada mas estava ictérica. Ficou em incubadora durante as primeiras 24 horas; nos 15 dias seguintes permaneceu abatida, prostrada, reagindo pouco a estímulos externos; choro fraco; urina amarelada e carregada que manchava a roupa. Com um ano de idade a paciente não sentava nem engatinhava; movimentava pouco os quatro membros. Aos dois anos de idade manifestou pequena melhora conseguindo erguer-se quando se apoiava em uma parede e, segura pelas axilas, esbocava troca de passos apressados; nāo falava. Aos 3 anos de idade teve crise convulsiva, representada por "repuxamentos" na hemiface e membros do lado direito, que se repetiu após 8 meses. Entre os 3 e 4 anos de idade aprendeu por si mesma a utilisar os pés para apanhar objetos e, na ocasião em que foi internada, era capaz de pegar um palito de fósforo com o pé direito e riscá-lo na caixa que mantinha presa entre os dois pés; utilisava pouco os membros superiores, não andava, engatinhava sentada. Paciente agitada, chorando facilmente, irriquieta, contactuando bem pela audição e visão mas não cooperando no exame. Exame neurológico - Perímetro cefálico $48 \mathrm{~cm}$; distância ântero-posterior $28 \mathrm{~cm}$; distância biauricular $29 \mathrm{~cm}$. Som timpânico à percussão do crânio. Linguagem: disfasia motora. Facies não característíca. Atitude: a) em decúbito dorsal os membros superiores permanecem em flexão, sendo que o esquerdo com o braço em abdução, a mão em extensão e os quatro últimos dedos em flexão com o polegar em oponência (preso na mão fechada); os membros inferiores se conservam em extensão e sempre em movimentação ativa; b) sentada, se mantém à custa de preensão com os dedos dos pés nas grades do leito. A paciente não se mantém em pé e não anda. Nos membros superiores a motricidade é ampla embora os atos motores sejam precários; com os membros inferiores, principalmente o direito, a paciente consegue realizar vários atos motores tais como apreender com os dedos dos pés objetos de vários tamanhos (lápis, banana, colher, garfo, fosforo) e, segurando a boneca com o pé direito, acariciá-la com o esquerdo (Fig. 1). Força muscular conservada. A movimentação passiva, hipertonia dicreta dos grupos flexores dos membros superiores (braço e antebraço), sendo que, na mão, esta hipertonia atinge os flexores dorsais do punho e flexores dos dedos; nos membros inferiores a hipertonia é em extensão. Tentando falar, a paciente emite sons não articulados; mímica inadequada e sem propósito não tendo relação com as emoçōes; mastigação, deglutição e respiração sem alterações. Motricidade involuntária espontânea, ausente. Motricidade reflexa sem alterações, estando presentes e simétricos os reflexos miotáticos de estiramento; dentre os reflexos cutâneos, os abdominais presentes e simétricos; reflexo plantar com Babinski bllateral. Sensibilidade aparentemente conservada. Nervos cranianos sem alterações. Exames complementares - Liquido cefalorraqueano em puncão suboccipital, normal. Pneumencefalografia normal. Craniograma normal. Radiografia de ossos longos: idade óssea individual média ao redor de 2 anos e meio; ausência de estigmas ósseos. Reação de Mantoux negativa. Exame hematológico normal. Reaçóes sorológicas para sífilis negativas. Eletrencefalograma normal para a idade durante vigilia e sono barbitúrico; o resultado do exame sob estimulação auditiva foi inconclusivo. Com os dados da anamnese, do exame clínico e exames subsidiários foi firmado o diagnóstico de "Seqüelas de encefalopatia billirrubínica", sendo a paciente encaminhada para tratamento no setor de reeducação neuro-muscular. 

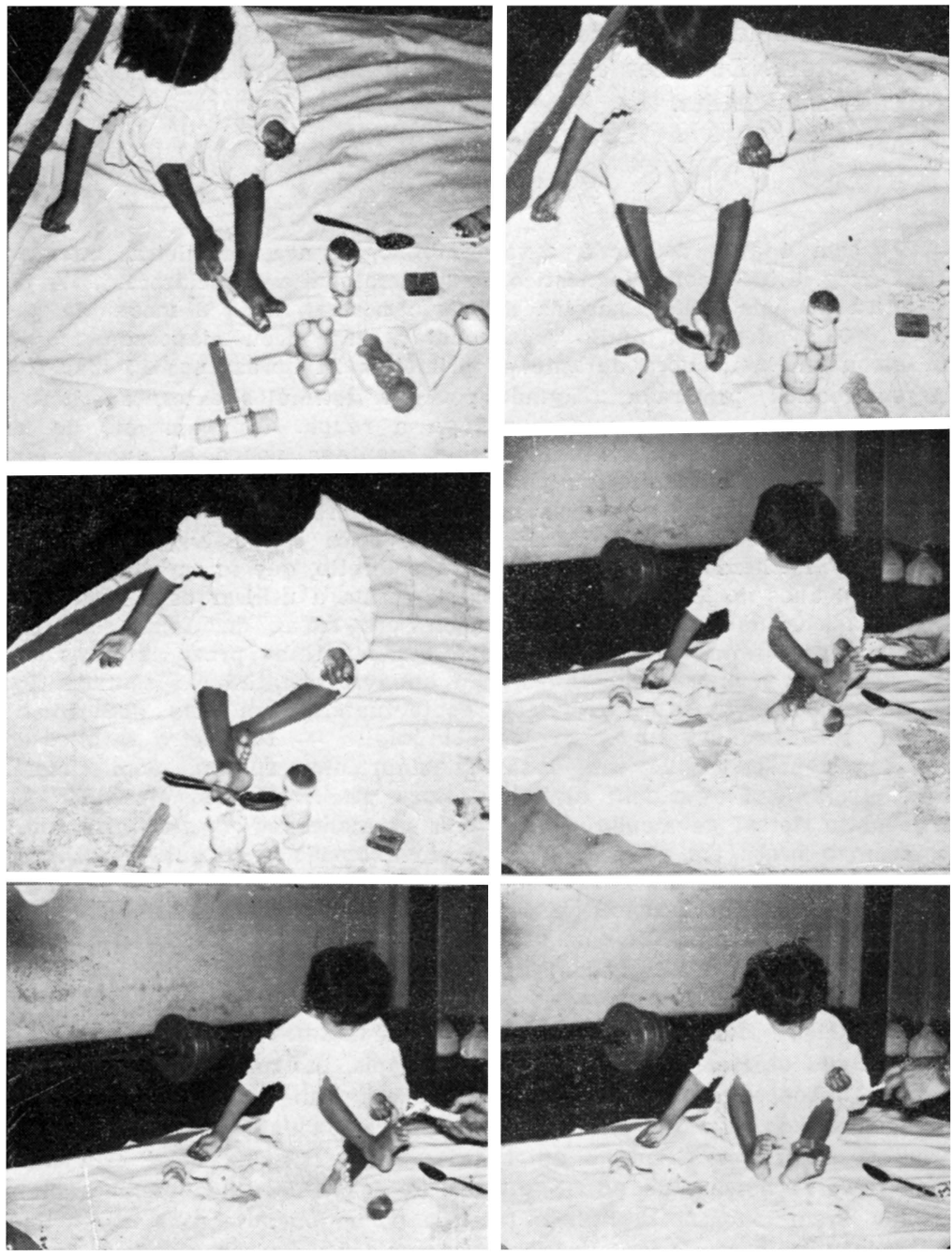

Fig. 1 - Caso S.A.P. Atos motores que a paciente executava com os pés: descascar banana; raspar banana com colher; alimentar a boneca; tirar um cigarro do maço; riscar fósforo na caixa para acender o cigarro.

Evolução e tratamento - Medicada com tranquilizantes até 15-3-1963, a paciente estava mais calma e colaboradora ao ser encaminhada ao setor de cinesiterapia; após avaliação da capacidade motora, foi traçado programa de reeducação visando desenvolver principalmente a preensão manual, o equilíbrio e a marcha (Fig. 2). Em 29-3-1963 a paciente passou a segurar objetos com as mãos, preferivelmente com a direita, sem muita firmeza. Em 5-4-1963 passou a segurar objetos com firmeza, embora não conseguisse utilizá-los. Em 18-4-1963 conseguia abrir bem a mão direita e os três ũltimos dedos da mão esquerda; com a direita conseguia tirar rodelas que estavam encaixadas em uma haste; conseguia ficar em pé encostada à parede, com 

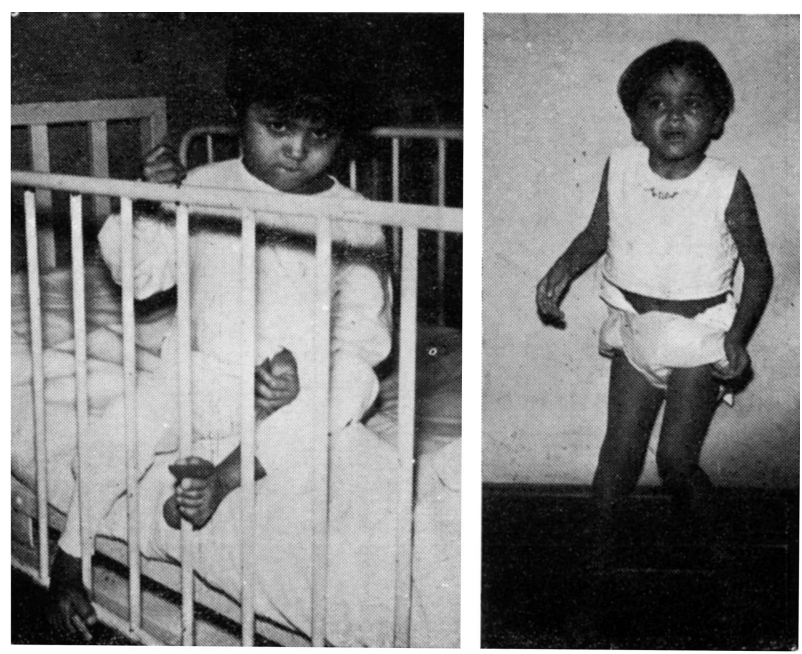

Fig. 2-Caso S.A.P. Posturas da paciente por ocasião da internação: sentada (preensão das grades da cama com os artelhos); em pé, encostada à parede.

os membros inferiores semifletidos; colocada no andador trocava passos para traz (Fig. 3). Em 22-4-1963 a preensão havia melhorado bastante e a paciente conseguia andar sem dificuldade no carrinho. Continuou a melhorar lenta e progressivamente e, em 29-4-1963, teve alta hospitalar; a mãe da paciente foi orientada no sentido de continuar o programa de reeducação em casa, com retorno ao Ambulatório. Ao ser reexaminada, em 29-5-1963, já fazia uso das mãos para preensão e alimentação, conseguindo descascar uma banana sem auxílio (Fig. 4); permanecia em pé, embora encostada à parede; conseguia trocar passos com pouco apôio. A partir de então não retornou ao ambulatório.

\section{COM ENTARIOS}

Trata-se de uma criança com lesões cerebrais difusas conseqüentes, provavelmente, a encefalopatia bilirrubínica. O baixo nível cultural dos pais, bem como o descuido dos mesmos permitiu que a criança se desenvolvesse sem qualquer tipo de aprendizado. Aos 4 anos de idade a paciente apresentava acentuado retardo mental, retardo no aprendizado da fala, irritabilidade; em virtude de não ter aprendido a utilizar as mãos, desenvolveu de forma curiosa uma certa habilidade com os pés, conseguindo realizar com eles atos motores até certo ponto delicados; por outro lado, os membros superiores e, em particular, as mãos permaneciam sem qualquer função.

Durante 3 meses a paciente foi submetida a programa de exercícios que visavam ao aprendizado e desenvolvimento de atos motores com os membros superiores, particularmente a preensão; ao mesmo tempo foram instituídos exercícios para postura e equilíbrio estático bem como para desenvolver a marcha. O reexame da paciente após esse período evidenciou nítida melhora 

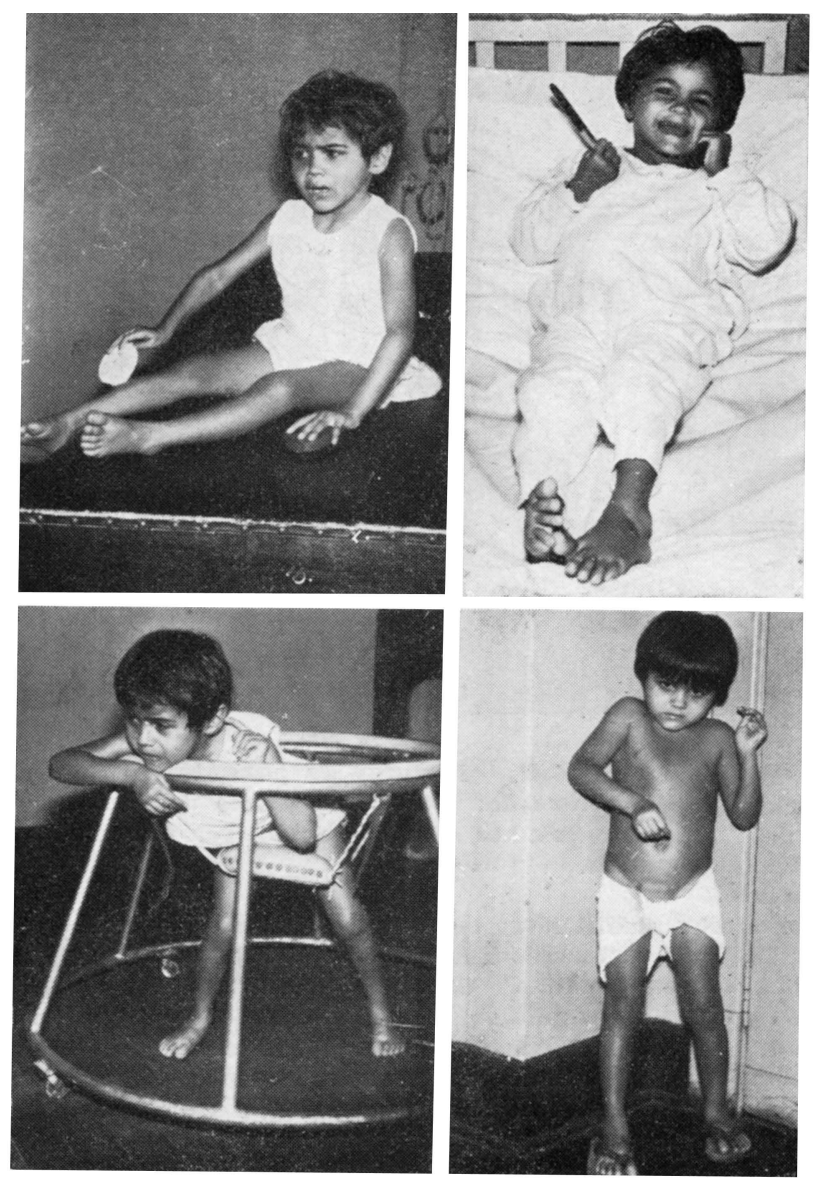

Fig. 3 - Caso S.A.P. Exercícıos de reeducação: em $A$ e $B$ exercicios para objetos de porte médio; em $C$, exercícios para a marcha; em $D$, paciente em pé, apoiada na parede.
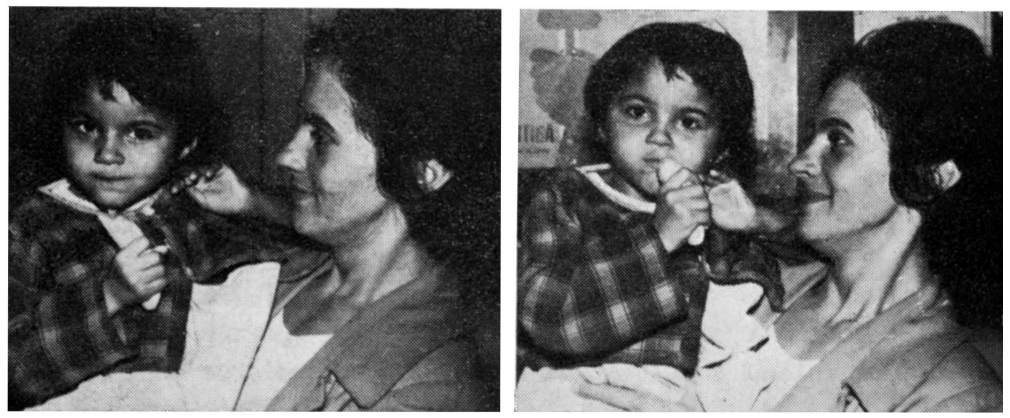

Fig. 4 - Caso S.A.P. Paciente 30 dias após a alta hospitalar, conseguindo apreender alimentos e os levar à boca. 
do quadro. Muito embora a correlação entre reeducação e recuperação da função perdida após lesões cerebrais extensas constitua assunto controvertido, parece que os vários autores são concordes em admitir que um programa de reabilitação diminua o tempo de retorno da função.

Por outro lado, até que ponto o retorno da função se faz espontâneamente, constitui questão aberta à discussão. Assim, para Forgays ${ }^{1}$, desde que não existe limite de tempo para o aparecimento do efeito de diásquise, torna-se necessário que decorra tempo bastante longo após a lesão, para se considerar que não há possibilidade de reeducação.

No caso presente se procurou evidenciar a utilidade de um programa de exercícios para recuperar as funçōes motoras de uma paciente com lesc̃es extensas do sistema nervoso central e na qual, decorrido tempo bastante longo, as funções motoras dos membros se desenvolveram de forma invertida.

Acreditamos que se a paciente não tivesse sido submetida a um programa de reeducação sistemático, ela continuaria a desenvolver ainda mais as funções de preensão com os pés e talvez jamais conseguisse andar. Por isso acreditamos que, no caso presente, as funções que não se desenvolveram espontâneamente, puderam ser recuperadas mediante reeducação.

É evidente, por outro lado, que o programa de exercícios de reeducação não tem limites precisos, devendo-se aguardar estudos ulteriores que permitam melhor controle das possibilidades relacionadas com o problema do reaprendizado e retorno das funções após lesōes cerebrais.

\section{R E S M O}

Os autores registram o caso inusitado (na literatura consultada não há referência a caso semelhante) de uma paciente com 4 anos de idade, com distúrbios neurológicos e atraso psíco-motor decorrentes de provável encefalopatia bilirrubínica. Entre os sintomas era mais nítida a inversão de funções motoras entre os membros superiores e inferiores. Submetida a programa de exercícios de reeducação a paciente melhorou de forma bastante satisfatória; por ocasião da alta hospitalar, três meses depois da internação, já utilizava os membros superiores para a preensão e manutenção de objetos; nessa ocasião a paciente já ficava em pé apoiada e trocava passos com apôio.

Diante de tais fatos os autores admitem que, no caso presente, as funções perdidas que não se recuperaram espontaneamente obtiveram considerável melhora mediante programa de reeducação motora.

\section{S U M M A R Y}

Reeducation and restitution of motor function: a case report of reversal of functions between the lower and upper extremities

The unusual case of a 4-year-old girl with the probable diagnosis of kernicteurs, having psychomotor retardation and showing a reversal of 
functions between the lower and upper extremities is reported. Submitted to adequate training the patient improved markedly, and at a 3 months interval, she already used satisfactorily her hands, could stand leaning against the wall and was able to walk with support. The findings in this case suggest that at least some of the lost functions which do not recover spontaneously are able to return through an adequate reeducation program.

\section{REFERENCIAS}

1. FORGAY, D. C. - A note on re-education and restitution of function. J. nerv. ment. Dis. 118:365, 1953.

2. LASHLEY, K. S. - Factors limiting recovery after central nervous lesions. J. nerv. ment. Dis. 88:733, 1938.

Clinica Neurológica - Faculdade de Medicina, Universidade de São Paulo Caixa Postal 3461 - 01000 São Paulo, SP - Brasil. 